\title{
Dissipation of excess excitation energy of the needle leaves in Pinus trees during cold winters
}

\author{
AO Zhang ${ }^{1,2} \cdot$ Zhen-Hai Cui $^{1,3} \cdot$ Jia-Lin $\mathrm{Yu}^{1} \cdot \mathrm{Zi}^{1-L i n g ~ H u}{ }^{1} \cdot$ Rui Ding ${ }^{1,2}$. \\ Da-Ming Ren ${ }^{1} \cdot$ Li-Jun Zhang ${ }^{1,2,3}$
}

Received: 7 February 2016 /Revised: 19 April 2016 / Accepted: 30 April 2016 / Published online: 19 May 2016

(C) The Author(s) 2016. This article is published with open access at Springerlink.com

\begin{abstract}
Photooxidative damage to the needle leaves of evergreen trees results from the absorption of excess excitation energy. Efficient dissipation of this energy is essential to prevent photodamage. In this study, we determined the fluorescence transients, absorption spectra, chlorophyll contents, chlorophyll $a / b$ ratios, and relative membrane permeabilities of needle leaves of Pinus koraiensis, Pinus tabulaeformis, and Pinus armandi in both cold winter and summer. We observed a dramatic decrease in the maximum fluorescence $\left(F_{\mathrm{m}}\right)$ and substantial absorption of light energy in winter leaves of all three species. The $F_{\mathrm{m}}$ decline was not correlated with a decrease in light absorption or with changes in chlorophyll content and chlorophyll $a / b$ ratio. The results suggested that the winter leaves dissipated a large amount of excess energy as heat. Because the cold winter leaves had lost normal physiological function, the heat dissipation depended solely on changes in the photosystem II supercomplex rather than the xanthophyll cycle. These findings imply that more attention should be paid to heat dissipation via changes in the photosystem complex structure during the growing season.
\end{abstract}

AO Zhang and Zhen-Hai Cui are joint first authors.

Da-Ming Ren

daming_ren@hotmail.com

Li-Jun Zhang

ljzhang@syau.edu.cn

1 College of Biological Sciences and Technology, Shenyang Agricultural University, Shenyang 110866, China

2 College of Agronomy, Shenyang Agricultural University, Shenyang 110866, China

3 Liaoning Province Research Center of Plant Genetic Engineering Technology, Shenyang 110866, China
Keywords Pinus koraiensis $\cdot$ Pinus tabulaeformis $\cdot$ Pinus armandi . Chlorophyll fluorescence $\cdot$ Photoinhibition . Absorption spectrum $\cdot$ Xanthophyll cycle $\cdot$ Photosystem complex

\section{Introduction}

Evergreen pine (Pinus spp.) trees are widely distributed throughout the world and play important ecological roles. Although some species have stronger tolerance to cold than others, their needle leaves are often damaged during winter (Öquist and Huner 1991; Lehner and Lütz 2003; Rammig et al. 2010). This damage is due not only to low temperature, but also to strong light (García-Plazaola et al. 1999; Blennow and Lindkvist 2000), with intense radiation often compounding the damage by low temperature (Yamazaki et al. 2003). In contrast, the needle leaves can endure lower temperatures under weak illumination. Light is the energy source for plant photosynthesis, but light energy will damage the photosynthetic apparatus when more is absorbed by leaves than is consumed by photosynthesis (Murata et al. 2007). This process is referred to as photoinhibition. The excess excitation energy that is not used by photosynthesis generates reactive oxygen species (ROSs) and results in photooxidation damage of the photosynthetic apparatus (Nishiyama et al. 2001; Horton 2012; Tyystjarvi 2013). The degree of the photodamage depends on the clearance of ROSs (Mishra et al. 1993; Hwang et al. 2004; Murata et al. 2012), protection of the photosynthetic apparatus (Murchie and Niyogi 2011; Ruban et al. 2012), and repair of damaged structures and proteins (Takahashi and Badger 2011; Allahverdiyeva and Aro 2012; Goh et al. 2012). However, the first line of defense against photodamage is to decrease the excess energy.

Plants have several mechanisms to avoid excitation energy surplus, including: (1) decreasing the absorption of light 
energy (Jiang et al. 2006) by, in some species, altering the angle of their leaves under strong light (Rubio et al. 2007); (2) enhancing photorespiration (Osmond et al. 1997); and (3) increasing the dissipation of excess energy (Allahverdiyeva and Aro 2012). In the growing season, some plants can engage all three mechanisms. However, in cold winters with very low temperature $\left(-10\right.$ to $\left.-20^{\circ} \mathrm{C}\right)$, evergreen leaves lost or seriously weaken the ability to regulate their physiological activities and depend mainly on the dissipation to reduce the energy surplus.

The excess energy absorbed by plant leaves is dissipated as fluorescence and heat (Allahverdiyeva and Aro 2012). Fluorescence release is common when photosynthesis is impeded by strong light. The amount of released fluorescence varies with the changes in the structure of the photosystem complex, for instance, the disassociation of the photosystem II (PSII) light-harvesting complex from the PSII supercomplex (Tikkanen and Aro 2012). For heat dissipation during the growth season, the excess energy is released via the xanthophyll cycle (Eskling et al. 1997; Jahns and Holzwarth 2012), which involves the enzymatic interconversion between violaxanthin and zeaxanthin in higher plants and depends on the $\mathrm{pH}$ differential across the thylakoid membrane (Bratt et al. 1995; Büch et al. 1995). However, the same leaves of evergreen trees are quite different in physiological status such as photosynthesis, respiration, enzyme activity, and membrane permeability between in cold winter and in summer. Therefore, they may have a different mechanism of excess energy dissipation and the process in the cold winter might involve less enzymatic reactions. In this experiment, we compared the fluorescence transients, light absorption spectra, chlorophyll contents, and relative membrane permeabilities of the needle leaves of three Pinus species in the cold winter and summer to analyze their mechanisms of excess energy dissipation during cold winter.

\section{Materials and methods}

\section{Plant samples}

The plants used in this study were specimens of Pinus koraiensis (height 7.2-8.5 m, diameter at breast height 16.3$18.1 \mathrm{~cm}$, tree age 48 years), Pinus tabulaeformis (height 10.1$11.3 \mathrm{~m}$, diameter at breast height $26.9-29.4 \mathrm{~cm}$, tree age 31 years), and Pinus armandi (height 7.9-9.1 m, diameter at breast height $21.0-23.3 \mathrm{~cm}$, tree age 41 years) growing in the botanic garden of Shenyang Agricultural University, Shenyang city, Liaoning Province, China $\left(41^{\circ} 82^{\prime} \mathrm{N}, 123^{\circ}\right.$ $56^{\prime}$ E). P. koraiensis and P. tabulaeformis are native species and widespread in the northeast of China $\left(38^{\circ} \mathrm{N}-56^{\circ} \mathrm{N}\right)$ and $P$. armandi is an introduced species with less cold resistance. Three plants were chosen for measurement from each species. Twigs were cut off from the top of branches on the sunlit side and taken to the laboratory. The test was replicated three times. The winter samples were taken in late January 2012, when the air temperature ranged from -20 to $-7{ }^{\circ} \mathrm{C}$ (average, $-17.8^{\circ} \mathrm{C}$ ). The summer sampling was in late June 2013 (air temperature, $18-31{ }^{\circ} \mathrm{C}$; average $23{ }^{\circ} \mathrm{C}$ ).

\section{Measurement of fluorescence transients}

Needle leaves from the bases of twigs were subjected to darkness for $15 \mathrm{~min}$ and then exposed to $3000 \mu \mathrm{mol} \mathrm{m}^{-2} \mathrm{~s}^{-1}$ photon flux density generated by a Plant Efficiency Analyzer (HandyPEA) (Hansatech, Kings Lynn, Norfolk, UK) for $1 \mathrm{~s}$ (Strasser and Strasser 1995) to determine fluorescence induction curves. According to the fluorescence transients (OJIP) (Guissé et al. 1995; Strasser et al. 2004), the following parameters were obtained: (1) $F_{\mathrm{o}}$, the initial fluorescence yield; (2) $F_{\mathrm{m}}$, the maximum fluorescence; and (3) $F_{\mathrm{v}}$, the variable fluorescence.

\section{Measurement of absorbance spectra, chlorophyll content, and relative membrane permeability}

Absorbance spectra were measured with a portable Unispec SC spectrometer (PP Systems, Amesbury, MA, USA). Data were analyzed by Multispec 5.1.5. Chlorophyll content and the chlorophyll $a / b$ ratio were measured according to Arnon (1949). The relative membrane permeability of the middle parts of needle leaves was measured according to Bao et al. (2009).

\section{Data analysis}

Statistical analyses were performed using SPSS 13.0 (IBM, Chicago, IL, USA).

\section{Results}

\section{Fluorescence transients and parameters}

Fluorescence transients reflect the excitation energy distribution in the photosynthetic energy absorption and transfer system. As shown in Fig. 1, the needle leaves in cold winter showed atypical OJIP curves. The values of the $\mathrm{O}$ points $\left(F_{\mathrm{o}}\right)$, P points $\left(F_{\mathrm{m}}\right)$ and $F_{\mathrm{v}}\left(F_{\mathrm{m}}-F_{\mathrm{o}}\right)$, and the ranges of the $F_{\mathrm{v}} / F_{\mathrm{m}}$ ratio in the winter needles were much lower than in the summer ones (Table 1). The analysis of variance showed that the differences of these chlorophyll fluorescence parameters were significant or extremely significant between in the winter and summer as shown in Table 1 . These results suggested that the photochemical activities $\left(F_{\mathrm{v}}\right)$ in the winter needles were extremely weak. Notably, $F_{\mathrm{m}}$ values in the winter were remarkably lower than in the summer; this decrease might result from lower light energy absorption or greater release of absorbed energy release in forms other than fluorescence. 
Fig, 1 The comparison of chlorophyll fluorescence transients of needles in Pinus trees between in cold winter and summer

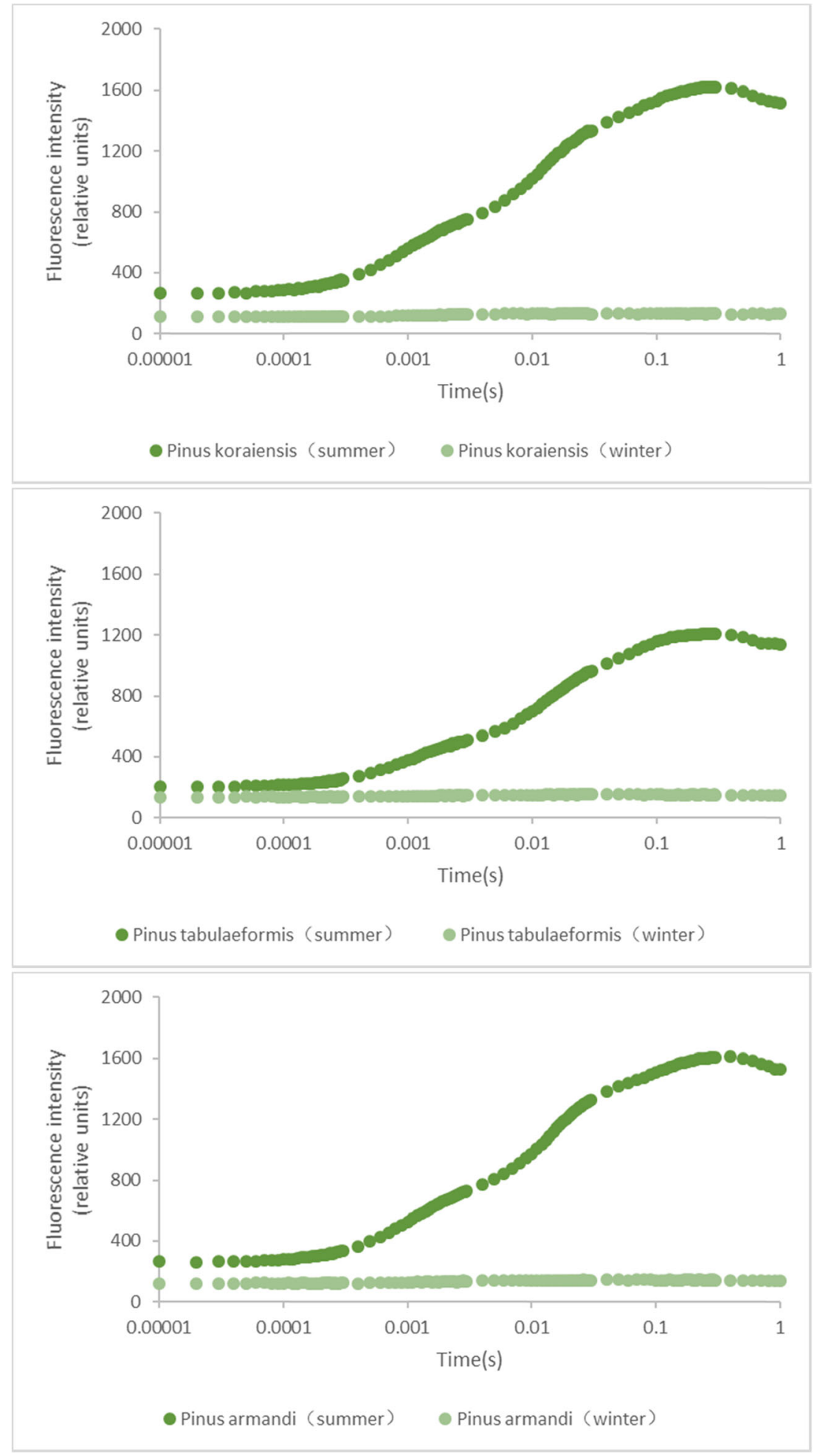

\section{Absorption spectra}

During very cold winter, photochemical activity is limited by low temperatures, and the needles cannot convert light energy to chemical energy via the photosynthetic electron transfer chain. In this circumstance, all light energy absorbed by leaves is excess excitation energy. To reduce this excess, the needles may decrease light energy absorption. As Fig. 2 shows, in cold winter, the needles absorbed less light energy in the visible range $(400-740 \mathrm{~nm})$ than in summer. For instance, the absorbances in summer and winter were, respectively, 92.7 and 86.7 \% in P. koraiensis, 91.8 and $85.9 \%$ in P. tabulaeformis, 
Table 1 The comparison of chlorophyll fluorescence parameters of needles in Pinus trees between in cold winter and summer

\begin{tabular}{lllccc}
\hline Species & Season & Fo & Fm & Fv & Fv/Fm \\
\hline P. koraiensis & Winter & $109 \pm 19.85^{* *}$ & $136 \pm 25.02^{* *}$ & $27 \pm 10.30^{* *}$ & $0.20 \pm 0.06^{* *}$ \\
& Summer & $260 \pm 27.83^{* *}$ & $1621 \pm 203.44^{* *}$ & $1361 \pm 180.10^{* *}$ & $0.84 \pm 0.01^{* *}$ \\
P. tabulaeformis & Winter & $135 \pm 22.50^{* *}$ & $154 \pm 17.78^{* *}$ & $18.67 \pm 4.73^{* *}$ & $0.12 \pm 0.05^{* *}$ \\
& Summer & $200 \pm 15.93^{* *}$ & $1209 \pm 83.78^{* *}$ & $1009 \pm 76.01^{* *}$ & $0.83 \pm 0.01^{* *}$ \\
P. armandi & Winter & $121 \pm 3.06^{* *}$ & $147 \pm 6.93^{* *}$ & $26.33 \pm 4.16^{* *}$ & $0.17 \pm 0.02^{* *}$ \\
& Summer & $255 \pm 27.91^{* *}$ & $1625 \pm 213.53^{* *}$ & $1370 \pm 215.53^{* *}$ & $0.84 \pm 0.03^{* *}$ \\
\hline
\end{tabular}

**Significance at $P \leq 0.01$ and 92.9 and $86.3 \%$ in P. armandi. These results showed that the leaves in winter still absorbed a large amount of light energy and needed to dissipate a great deal of excess energy. In addition, the decrease in light energy absorption in the winter was not proportional to that in $F_{\mathrm{m}}$. In all three species, we also observed a significant decrease in absorption in the winter in the infrared light region. The significant decreases in absorption in the UV range were also found in the winter in $P$. koraiensis and $P$. tabulaeformis, but $P$. armandi maintained the same low absorption in the winter and summer. The significance of these changes could not be interpreted.

\section{Chlorophyll content and chlorophyll $a / b$ ratio}

In this study, the chlorophyll contents and chlorophyll $a / b$ ratios of the needle leaves from the three pine species did not change consistently between the cold winter and summer (Fig. 3). The analysis of variance showed that the values of both parameters in $P$. koraiensis were not significantly different $(P \geq 0.05)$ in the winter and summer, both values in $P$. tabulaeformis were significantly higher $(P \leq 0.05$ or $\leq 0.01)$ in winter than in summer and both values in $P$. armandi were significantly lower $(P \leq 0.01)$ in winter than in summer. Obviously, changes in the chlorophyll content and chlorophyll $a / b$ ratio were not correlated with the $F_{\mathrm{m}}$ decrease in the winter.

\section{Relative membrane permeability}

Relative membrane permeability reflects the structural integrity and functional status of the cell membrane. In severe cold, the cell membrane loses its normal double-layer structure and normal function. In winter, the relative membrane permeabilities of the needle leaves from $P$. koraiensis, $P$. tabulaeformis, and $P$. armandi were $74.2,57.8$, and $62.2 \%$, respectively (Fig. 4). The analysis of variance showed that the relative membrane permeabilities in winter were significantly higher $(P \leq 0.01)$ than in summer. These results showed that the leaves had lost normal physiological activity in winter.

\section{Discussion and conclusions}

Normally, light energy absorbed by leaves is mainly used to reduce carbon dioxide during photosynthesis. When the absorbed energy exceeds the photosynthetic need, the excess energy will dissipate in the form of fluorescence and heat (Allahverdiyeva and Aro 2012; Horton 2012). Although the amount of energy released in fluorescence is a small part of the total energy dissipation, the fluorescence intensity varies with environmental changes (Murata et al. 2007) and with the physiological status of the leaves (Jiang et al. 2006). In this study, the leaf $F_{\mathrm{m}}$ values in winter leaves were much lower than those in summer in three pine species (Fig. 1 and Table 1). The lower $F_{\mathrm{m}}$ values may be caused by a decrease in light energy absorption or an increase in photochemical reactions and heat dissipation. Nevertheless, the chlorophyll contents and chlorophyll $a / b$ ratios varied with species between the winter and summer (Fig. 3) and did not show a coincident change. Obviously, chlorophyll was not the cause of the $F_{\mathrm{m}}$ decrease in winter. The leaves in winter could not have increased their photochemical reaction rate either, because their biomembranes were non-functional (Fig. 4). In addition, the decrease in light energy absorption in the winter (Fig. 2) was not proportional to the decline in $F_{\mathrm{m}}$ value (Fig. 1 and Table 1). Therefore, the lower $F_{\mathrm{m}}$ was mainly attributed to an increase in heat dissipation.

The xanthophyll cycle is an important mechanism for dissipating excess excitation energy as heat (Eskling et al. 1997) during mild winters (Martínez-Ferri et al. 2004). This process involves the enzyme-catalytic interconversion between violaxanthin and zeaxanthin in higher plants (Jahns et al. 2009; Jahns and Holzwarth 2012). During excess light stress, violaxanthin is converted to the intermediate antheraxanthin and then zeaxanthin by violaxanthin de-epoxidase, which requires an acidic $\mathrm{pH}$ to bind to the thylakoid membrane (Bratt et al. 1995); the reverse reaction is catalyzed by zeaxanthin epoxidase (Schaller et al. 2012), which functions at $\mathrm{pH} 7.5$ and needs a supply of nicotinamide adenine dinucleotide phosphate, flavin adenine dinucleotide, and $\mathrm{O}_{2}$ (Büch et al. 1995). Thus, the operation of the xanthophyll cycle depends on the integrity and normal function of the chloroplast membrane. But in the present study, the relative membrane 
Fig. 2 The comparison of absorbance spectra of needles in Pinus trees between in cold winter and summer

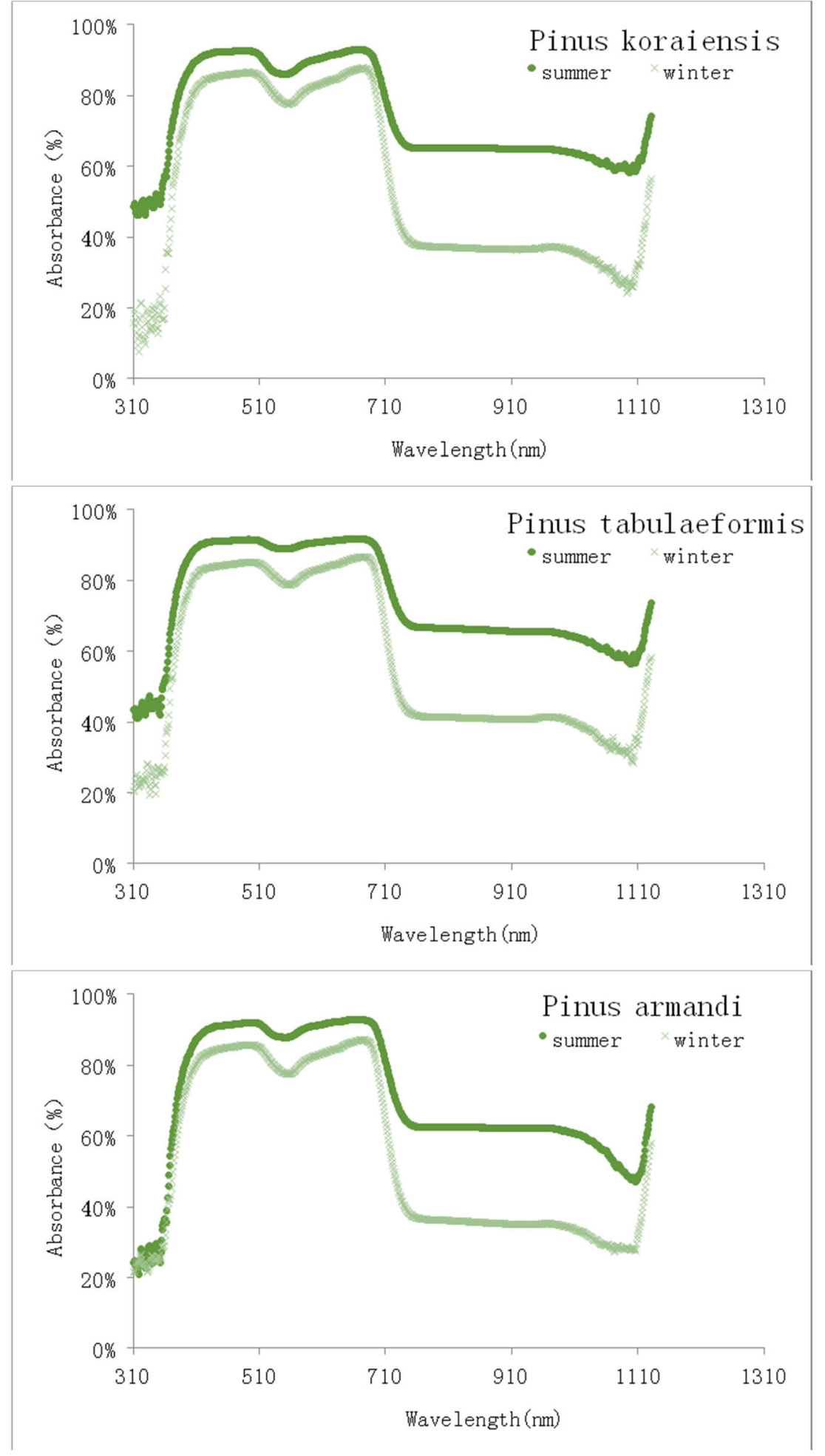

permeability of the winter needles was $57.8-74.2 \%$, suggesting the chloroplast membranes had lost their normal structure and physiological functions. Lütz (1996) reported that green leaves of Eriophorum that experienced a sudden frost and strong irradiation suffered yellow leaf areas, and high zeaxanthin levels in the affected areas did not prevent the damage.
Therefore, we inferred that the heat dissipation of excess energy in the cold winter did not depend on cell function and enzyme activity.

The PSII supercomplex in higher plants contains a reaction center and several light-harvesting pigment complexes (LHCII) (Caffarri et al. 2009). When the green leaves 
Fig. 3 The comparison of chlorophyll content and chlorophyll $\mathrm{a} / \mathrm{b}$ ratio of needles in Pinus trees between in cold winter and summer. The error bar is SD. $a, b$ significance at $P \leq 0.01,0.05$, respectively

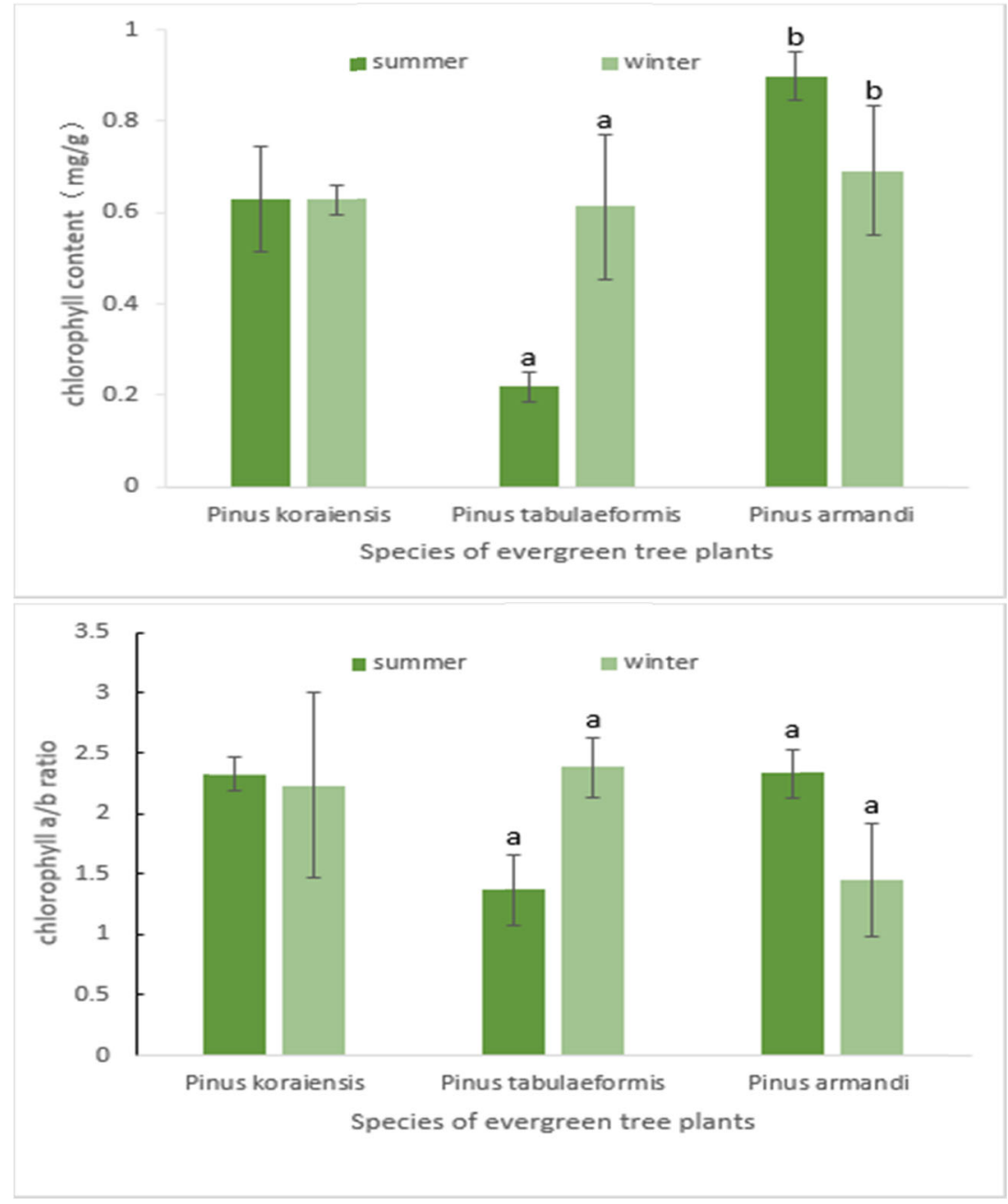

photosynthesize, light energy absorbed by LHCII is transferred to the PSII reaction center, then passes through the cytochrome $b_{6}-f$ complex and other transfer intermediates to reach photosystem I (PSI), and is finally used to reduce NADP. While the reaction centers are in close state, the amount of fluorescence released is $F_{\mathrm{m}}$, which represents the photochemical reaction potential (Strasser and Strasser 1995). Several factors influence the value of $F_{\mathrm{m}}$, including the state transition and changes in the PSII supercomplex structure (Tikkanen and Aro 2012). During the state transition, LHCII
Fig. 4 The comparison of relative membrane permeability of needles in Pinus trees between in cold winter and summer. The error bar is SD. a significance at $P \leq 0.01$

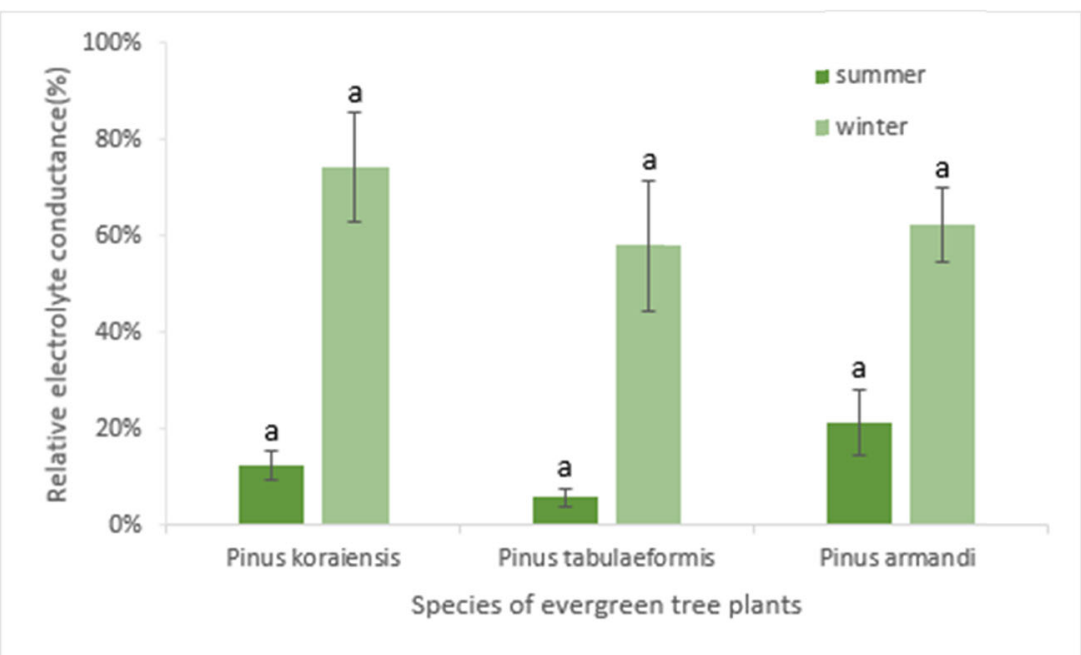


is phosphorylated, moves to the PSI complex (Tikkanen and Aro 2012; Cui et al. 2014), and transfers its energy to PSI reaction center so as to decrease $F_{\mathrm{m}}$. However, in the low temperatures of the present study, the winter leaves were unable to perform the state transition. Heat release from the PSII supercomplex is an important pathway of energy dissipation, and a relevant protein had been identified from Chlamydomonas reinhardtii (Elrad et al. 2002). Therefore, the decrease in leaf $F_{\mathrm{m}}$ in winter in these three pine species was mainly a result of changes in the PSII complex structure.

In conclusion, the maximum fluorescence of the leaves of the three pine trees decreased substantially in winter. The decrease was not due to a decline in light energy absorption, state transition, or heat dissipation via the xanthophyll cycle. Therefore, the $F_{\mathrm{m}}$ decrease possibly involved the changes in the PSII supercomplex. This result implies that more attention should be paid to heat dissipation resulting from alterations to the PSII complex architecture during the growing season. Further work is needed to explore the characteristics of the PSII complex architecture in winter and the mechanism of the structural alteration as air temperature declines seasonally.

Open Access This article is distributed under the terms of the Creative Commons Attribution 4.0 International License (http:// creativecommons.org/licenses/by/4.0/), which permits unrestricted use, distribution, and reproduction in any medium, provided you give appropriate credit to the original author(s) and the source, provide a link to the Creative Commons license, and indicate if changes were made.

\section{References}

Allahverdiyeva Y, Aro EM (2012) Photosynthetic responses of plants to excess light: mechanisms and conditions for photoinhibition, excess energy dissipation and repair. In: Eaton-Rye JJ, Tripathy BC, Sharkey TD (eds) Photosynthesis: plastid biology, energy conversion and carbon assimilation. Advances in photosynthesis and respiration. Springer, Dordrecht, pp. 275-297

Arnon DI (1949) Copper enzymes in isolated chloroplasts: polyphenoloxidase in Beta vulgaris. Plant Physiol 9:1-15. doi:10. 1104/pp24.1.1

Bao A, Wang S, Wu G, Xi J, Zhang J, Wang C (2009) Overexpression of the Arabidopsis $\mathrm{H}+-$ PPase enhanced resistance to salt and drought stress in transgenic alfalfa (Medicago sativa L.). Plant Sci 176:232240

Blennow K, Lindkvist L (2000) Models of low temperature and high irradiance and their application to explaining the risk of seedling mortality. Forest Ecol Manag 135:289-301

Bratt CE, Arvidsson PO, Carlsson M, Åkerlund HE (1995) Regulation of violaxanthin de-epoxidase activity by $\mathrm{pH}$ and ascorbate concentration. Photosynth Res 45:169-175

Büch K, Stransky H, Hager A (1995) FAD is a further essential cofactor of the NAD $(\mathrm{P}) \mathrm{H}$ and $\mathrm{O} 2$-dependent zeaxanthin-epoxidase. FEBS Lett 376:45-48

Caffarri S, Kouřil R, Kereïche S, Boekema EJ, Croce R (2009) Functional architecture of higher plant photosystem II supercomplexes. EMBO J 28:3052-3063
Cui Z, Wang Y, Zhang A, Zhang L (2014) Regulation of reversible dissociation of LHCII from PSII by phosphorylation in plants. Amer J Plant Sci 5:241-249

Elrad D, Niyogi K, Grossmanc AR (2002) Major light-harvesting polypeptide of photosystem II functions in thermal dissipation. Plant Cell 14:1801-1816

Eskling M, Arvidsson PO, Åkerlund HE (1997) The xanthophyll cycle, its regulation and components. Physiol Plant 100:806-816

García-Plazaola JI, Artetxe U, Becerril JM (1999) Diurnal changes in antioxidant and carotenoid composition in the Mediterranean sclerophyll tree Quercus ilex (L.) during winter. Plant Sci 143: 125-133

Goh CH, Ko SM, Koh S, Kim YJ, Bae HJ (2012) Photosynthesis and environments: photoinhibition and repair mechanisms in plants. $\mathrm{J}$ Plant Biol 55:93-101

Guissé B, Srivastava A, Strasser RJ (1995) The polyphasic rise of the chlorophyll $a$ fluorescence (OKJIP) in heat stressed leaves. Arch Sci Genev 48:147-160

Horton P (2012) Optimization of light harvesting and photoprotection: molecular mechanisms and physiological consequences. Phil Trans R Soc B 367:3455-3465

Hwang HJ, Kim JH, Eu YJ, Moon BY, Cho SH, Lee CH (2004) Photoinhibition of photosystem I is accelerated by dimethyldithiocarbamate, an inhibitor of superoxide dismutase, during light-chilling of spinach leaves. J Photochem Photobiol B 73: 79-85

Jahns P, Holzwarth AR (2012) The role of the xanthophyll cycle and of lutein in photoprotection of photosystem II. BBA-Bioenergetics 1817:182-193

Jahns P, Latowski D, Strzalka K (2009) Mechanism and regulation of the violaxanthin cycle: the role of antenna proteins and membrane lipids. BBA-Bioenergetics 1787:3-14

Jiang CD, Gao HY, Zou Q, Jiang GM, Li LH (2006) Leaf orientation, photorespiration and xanthophyll cycle protect young soybean leaves against high irradiance in field. Environ Exp Bot 55:7-96

Lehner G, Lütz C (2003) Photosynthetic functions of cembran pines and dwarf pines during winter at timberline as regulated by different temperatures, snowcover and light. J Plant Physiol 160:153-166

Lütz C (1996) Avoidance of photoinhibition and examples of photodestruction in high alpine Eriophorum. J Plant Physiol 148: $120-128$

Martínez-Ferri E, Manrique E, Valladares F, Balaguer L (2004) Winter photoinhibition in the field involves different processes in four cooccurring Mediterranean tree species. Tree Physiol 24:981-990

Mishra NP, Mishra RK, Singhal GSI (1993) Involvement of active oxygen species in photoinhibition of photosystem II: protection of photosynthetic efficiency and inhibition of lipid peroxidation by superoxide dismutase and catalase. J Photochem Photobiol B 19:19-24

Murata N, Takahashi S, Nishiyama Y, Allakhverdiev SI (2007) Photoinhibition of photosystem II under environmental stress. BBA-Bioenergetics 1767:414-421

Murata N, Allakhverdiev SI, Nishiyama Y (2012) The mechanism of photoinhibition in vivo: re-evaluation of the roles of catalase, $\alpha$ tocopherol, non-photochemical quenching, and electron transport. BBA-Bioenergetics 1817:1127-1133

Murchie EH, Niyogi KK (2011) Manipulation of photoprotection to improve plant photosynthesis. Plant Physiol 155:86-92

Nishiyama Y, Yamamoto H, Allakhverdiev SI, Inaba M, Yokota A, Murata N (2001) Oxidative stress inhibits the repair of photodamage to the photosynthetic machinery. EMBO J 20: 5587-5594

Öquist G, Huner NPA (1991) Effects of cold acclimation on the susceptibility of photosynthesis to photoinhibition in Scots pine and in winter and spring cereals: a fluorescence analysis. Funct Ecol 5: 91-100 
Osmond BY, Badger M, Maxwell K, Björkman O, Leegood R (1997) Too many photons: photorespiration, photoinhibition and photooxidation. Trends Plant Sci 2:119-121

Rammig A, Jonsson AM, Hickler T, Smith B, Barring L, Sykes MT (2010) Impacts of changing frost regimes on Swedish forests: incorporating cold hardiness in a regional ecosystem model. Ecol Model 221:303-313

Ruban AV, Johnson MP, Duffy CDP (2012) The photoprotective molecular switch in the photosystem II antenna. BBA-Bioenergetics 1817: 167-181

Rubio DCR, Vargas P, Pérez-Corona E, Manrique E, Quintana JR, García-Verdugo C, Balaguer L (2007) Field patterns of leaf plasticity in adults of the long-lived evergreen Quercus coccifera. Ann Bot 100:325-334

Schaller S, Wilhelm C, Strzałka K, Goss R (2012) Investigating the interaction between the violaxanthin cycle enzyme zeaxanthin epoxidase and the thylakoid membrane. J Photochem Photobiol B 114:119-125

Strasser BJ, Strasser RJ (1995) Measuring fast fluorescence transients to address environmental questions: the JIP test. In: Mathis P (ed)
Photosynthesis: from light to biosphere. Kluwer Academic, Dordrecht, pp. 977-980

Strasser RJ, Tsimilli-Michael M, Srivastava A (2004) Analysis of the chlorophyll $a$ fluorescence transient. In: GC P, Govindjee (eds) Advances in photosynthesis and respiration. Springer, Dordrecht, pp. 321-362

Takahashi S, Badger MR (2011) Photoprotection in plants: a new light on photosystem II damage. Trends Plant Sci 16:53-60

Tikkanen M, Aro EM (2012) Thylakoid protein phosphorylation in dynamic regulation of photosystem II in higher plants. BBABioenergetics 1817:232-238

Tyystjarvi E (2013) Photoinhibition of photosystem II. Int Rev Cell Mol Biol 300:243-303

Yamazaki JY, Ohashi A, Hashimoto Y, Negishi E, Kumagai S, Kubo T, Oikawa T, Kamimura Y (2003) Effects of high light and low temperature during harsh winter on needle photodamage of Abies mariesii growing at the forest limit on Mt. Norikura in Central Japan. Plant Sci 165:257-264 